\title{
METHODOLOGY FOR PERIODIC COMPLIANCE CONTROL OF COMPOSITE RESERVOIRS INSTALLATION IN MOTOR VEHICLES
}

\author{
Dragan Nikolić, \\ Predrag Popović, \\ Zoran Masoničić1, \\ Siniša Dragutinović, \\ Predrag Bralović, \\ Branko Spajić 1 \\ ${ }^{1}$ Vinca institute, \\ Belgrade, Serbia \\ ${ }^{2}$ Singidunum University, \\ 32 Danijelova Street, Belgrade, Serbia
}

\begin{abstract}
:
The paper points out the problem of periodic compliance control of composite reservoirs installation in motor vehicles and necessity of designing methodologies in this field. The survey indicated that with expert systems application periodic compliance of composite reservoirs installation can be achieved.

The paper presents the design of an expert system for visual control of composite tanks for storing compressed natural gas as a fuel for motor vehicles, using a shell expert system as a tool to design the knowledge base.

The knowledge base is designed using production rules. The expert system is tested on a concrete example. The research results point to the possibility of periodical compliance control of composite reservoirs installation in motor vehicles using the designed knowledge base. Also, the quality of visual control, reducing the time for analysis and reasoning on the state of composite reservoirs and auxiliary equipment for storing compressed natural gas as a fuel for motor vehicles, is achieved using the designed expert system.
\end{abstract}

Key words:

reservoirs installation, composite reservoirs, motor vehicles.

\section{INTRODUCTION}

Pursuant to regulations, standards and rulebooks of the Republic of Serbia, motor vehicles put into traffic must meet the appropriate conditions depending on the vehicle's category, motor fuel they use, their purpose, etc. The vehicles using compressed natural gas as motor fuel are subject to special regulations related to technical properties of the equipment and installations for compressed natural gas, to the instructions issued by the vehicle manufacturer, as well as to the Rulebooks on testing of vehicles using compressed natural gas as the vehicle motor fuel. Some of these rulebooks are the following: SRPS EN ISO 11439 - standard for reservoirs designed for storing natural gas under high pressure [17], UNECE R110 - rulebook for type approval of vehicles using CNG as motor fuel [15], SRPS ISO 19078 - standard related to control of reservoirs and installations for CNG. Professional and competent staff are performing visual control of composite reservoirs for storing compressed natural gas as a fuel for motor vehicles in accordance with the SRPS ISO 19078 [18] standard, which requires having experience and knowledge on reservoirs, installation, natural gas and visual control. 
However, in order for the procedure of visual control of composite reservoirs to be harmonized and unique when applied by all professional and competent individuals performing such visual control of composite reservoirs for storing CNG, there needs to be a harmonized methodology for periodic control of compliance of composite reservoirs installation in motor vehicles. The necessity towards harmonization of methodology for periodic control of compliance of composite tanks has led the authors to investigate possibilities of information system application to introduce systematic approach into the process of periodic control. The issue under observation is such that it requires information systems to have the knowledge base and possibility to make conclusions based on facts. One of possible directions of research to resolve the issue in question relates to designing an expert system that would enable systematic approach of periodic control of composite tanks for storing compressed natural gas as a fuel for motor vehicles.

\section{LITERATURE REVIEW}

Authors have noted that there is a frequent appearance of fire in buses using CNG if the reservoirs were compliant with the regulation ECE UN R110 [15]. Authors have stated that improvements are needed in the safety control system.

In the last 10 years, there has been an increase in the use of CNG motor fuel vehicles in Europe due to environment protection reasons $[6,9,7,14,16,19]$. According to 2005 data, it has been estimated that there are about 500,000 vehicles of different types in Europe (buses, passenger vehicles, etc) using CNG as motor fuel.

Most vehicles using CNG in traffic have been recorded in Italy, although the increase in the number of passenger vehicles using CNG is expected in many countries of the European Union due to numerous reliefs that owners of such vehicles get. Natural gas is stored in vehicles in metal or composite reservoirs under 200 bar pressure. Reservoirs in buses are serially connected (reservoir system) and placed at the top of the vehicle.

Compared to liquid fuels, the use of CNG in buses bears additional risks:

- explosion of reservoirs and accompanying pressure waves; reservoir fragments during explosion present individual danger; thermal effects as a result of joined explosion and combustion of released natural gas and ultimately explosive environment joined with pressure and thermal effects.
External causes such as traffic accidents, thermal impacts, etc, present main causes leading to the mentioned reservoir explosion accidents. Although regulations of UN ECE include all preventive actions to prevent accidents on vehicles using CNG as motor fuel from happening, recent accidents in France and Germany indicated the necessity of revision of this topic.

Zamanianet al [20] have indicated that air pollution in the last decade is an extremely great problem of capital and that the use of alternative fuels in vehicles is, therefore, one of solutions. Iran is the second largest global producer of natural gas, so the use of vehicles using CNG as motor fuel is extremely great. However, the authors state that different climatic area and sensitivity of natural gas need to be particularly considered due to probability of explosions. In 2009, Iran had 750,000 recorded vehicles using CNG. Iran is the fourth country in the world as per the number of vehicles using CNG. In order to examine the most frequent causes of accidents in vehicles using CNG, the authors used the Delfi method, i.e. a series of questionnaires in three series (where the results of the first series of questions were used to generate the second series of questions and so on successively in three series).

The first step in the examination was identification of experts who will provide answers to questions. Experts are professionals for CNG installation and safety who work at automobile factories, traffic police, etc. Questions asked to experts were to identify the most important parts of CNG system:

- Reservoir/s;

- Pressure indicator or fuel level indicator;

- Pressure reduction device (with temperature activation);

- Automatic valve of the reservoir;

- Manual valve;

- Pressure regulator;

- Gas flow regulator;

- Excess flow limiting device;

- Gas-air mixer (carburetor or injector);

- Filling unit or filling connector;

- Flexible fuel conduits;

- Rigid fuel conduits;

- Electronic control unit;

- Connectors;

- Gas-impermeable housing for components installed in the trunk and passenger sections. If the housing can be destroyed in fire, the pressure 
reduction device must be included in that gasimpermeable housing

- Non-return valve;

- Safety valve;

- CNG filter;

- Pressure and/or temperature transducer;

- Fuel selection system and electric system.

- Additional automatic valve may be combined with pressure regulator.

The following step in the research has been related to experts awarding evaluation to each component of the CNG system per level of importance based on their experience.

The experts considered the following components to be the most important from the safety aspect: safety valve, connector and rigid conduits. At the same time, these are also the critical elements where ruptures, leaks, etc, may occur.

The existing literature has no recorded research on application of expert systems for visual control of tanks for storing compressed natural gas, but there are papers on application of expert systems in diagnostics of malfunctions on motor vehicles $[8,13]$. There are also several patents related to designing of expert systems in motor vehicles $[1,3,10,12]$.

\section{DEVELOPING METHODHOLOGY}

The development of methodology for harmonization of periodic control of composite reservoirs installation in motor vehicles refers to defining methodological steps by which any control should be performed. Based on the rulebook R110 that refers to type approval of vehicles using CNG as motor fuel and long-term experience in the control of installation of composite reservoirs in motor vehicles, the following methodological steps have been formulated:

- preparatory activities,

- check of reservoir marking,

- control of installation of reservoir,

- control of reservoir installations,

- identification of reservoir surface damages,

- identification of reservoir impact damages,

- identification of reservoir thermal damages,

- identification of reservoir abrasive damages,

- identification of reservoir chemical damages,
- identification of reservoir atmospheric damages,

- report on the performed control.

In order to perform the stated methodological steps, a set of questions has been defined for the person authorized to perform visual control of composite reservoirs to ask in the stated scope and order to establish harmonization of periodic visual control of composite reservoir installation in motor vehicles. The defined list of control questions has been based on the rulebook R110 that refers to type approval of vehicles using $\mathrm{CNG}$ as motor fuel and long-term experience in the control of installation of composite reservoirs in motor vehicles, in the following way:

- Q1. Determining if preparatory activities have been performed (removal of dust from the reservoir, installation area) in order to be able to perform the visual control procedure;

- Q2. Determining if the reservoir marking has been performed in accordance with the standard requirements;

- Q3. Surveying the owner on any conditions or incidents that might have led to damages to the reservoir or installations;

- Q4. Determining if all installation blocks, girders and other components are in good condition and properly secured;

- Q5. Determining if the installation has been executed as per the current regulations;

- Q6. Determining if all components of the installation have been tightened and secured;

- Q7. Determining if the reservoir installation is properly vented;

- Q8. Determining if the line from PRD unit is designed for high pressure;

- Q9. Determining if the PRD unit is in good condition;

- Q10. Determining if the line connected to the reservoir is made to enable reservoir dilatations caused by internal pressure;

- Q11. Determining if there are damages to the installations caused by chemicals, abrasion, humidity, etc;

- Q12. Determining if the line connected to the vehicle is properly fixed with appropriate rubber backings in the span of about $60 \mathrm{~cm}$;

- Q13. Perform the procedure of visual control of reservoir surface for traces of surface damages 
(if there are traces of damages, determine if their depth is under $0.25 \mathrm{~mm}$ );

- Q14. Perform the procedure of visual control of reservoir surface for traces of impact damages (if there are traces of damages, determine if their depth is under $0.25 \mathrm{~mm}$ );

- Q15. Perform the procedure of visual control of reservoir surface for traces of abrasion damages (if there are traces of damages, determine if their depth is under $0.25 \mathrm{~mm}$ );

- Q16. Perform the procedure of visual control of reservoir surface for traces of thermal damages;

- Q17. Perform the procedure of visual control of reservoir surface for traces of chemical damages;

- Q18. Perform the procedure of visual control of reservoir surface for traces of atmospheric damages;

- Q19. Determining if there has been the reservoir discoloration, if there are bubbles, caps, etc.

- Q20. Determining if there is a minimum of $12.5 \mathrm{~mm}$ of gap between the reservoirs in installed position (gap not less than $9.5 \mathrm{~mm}$ is recommended for guards);

- Apply new control label if all Question's (Q1Q20) answers were Yes.

The stated methodological steps that would lead to harmonization of the procedure of periodic visual control of composite reservoirs installation in motors vehicles are the basis for building an expert system. The defined list of control questions has been rephrased into production rules in IF-THEN form. Answers to these questions, which are of the YES/NO form, are provided by a user [4].Connecting rules has been performed by chaining them in forward [11]. The rules are chained forwards up to the last one only if all criteria have been met for issuing the certificate on performed periodic control. If any of the control questions is not met, the expert system shall issue the final advice or conclusion to suspend the control procedure with the explanation that it is necessary to perform an appropriate activity of replacement, installation, tightening or repair at the authorized service. With rules chained in this way we obtained the inference mechanism represented by a decision tree, fig.1.

The expert system has been tested on a concrete example of composite reservoir. The Figure 2 presents a fragment of inference.

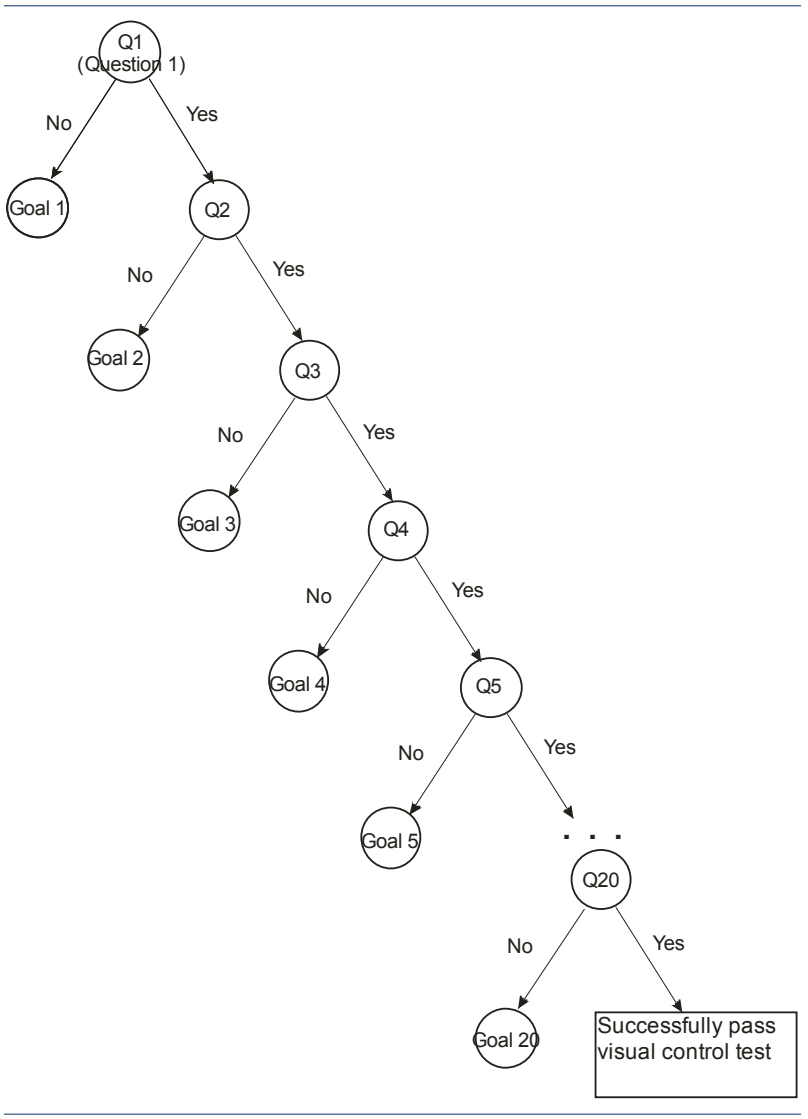

Figure 1. Decision tree

IF Q1: Have preparatory activities been performed (removal of dust from the reservoir, installation area) in order to be able to perform the visual control procedure? Yes

AND Q2: Has reservoir marking been performed in accordance with the standard requirements? Yes

AND Q3: Has surveying the owner on any conditions or incidents that might have led to damages to the reservoir or installations been performed? Yes

AND Q4: Are all installation blocks, girders and other components in good condition and properly secured? No

\section{THEN}

GOAL: Please secure all installation blocks, girders and other components and replace blocks/ girders/ components that are not in good condition and then proceed with visual control 
Based on the specific answers for the tank evaluated in the process of testing of the expert system for visual control of composite reservoirs for storing compressed natural gas as a fuel in motor vehicles, we obtained the finding that the installation blocks, girders and other components are not in good condition and/or properly secured, so expert system has suggested to secure all components if are they not well secured or replace components which are not in good condition, and then to proceed with visual control inspection.

\section{CONCLUSION}

The research demonstrated that the control of composite reservoirs for storing compressed natural gas as fuel in motor vehicles is an extremely present problem having in mind the number of motor vehicles in traffic, as well as forecasts of the number of motor vehicles to be in traffic in the forthcoming period. Having in mind the existing legal regulations in our country and the problem of non-compliance of the procedure for visual control of composite tanks for storing compressed natural gas as a fuel in motor vehicles at different motor vehicles testing centers in our country, the proposal is to further develop the methodology for harmonization of periodic visual control of composite reservoirs installation in motor vehicles.

Advantages of application of expert system for visual control of composite tanks for storing compressed gas as a fuel in motor vehicles are reflected in the systematic approach of the process for performing periodic visual control, while disadvantages of the same are reflected in the necessity of testing the designed solution and making conclusions on potential problems in exploitation based on operation in realistic conditions.

Further development of the expert system for visual control of composite tanks for storing compressed gas as a fuel in motor vehicles refers to addition of visual presentations of the observed installation system based on which the expert system could perform diagnostics. Likewise, extending the list of rules and improving the existing decision-making structure are also possible development directions for the expert system for visual control of composite tanks in motor vehicles.

\section{REFERENCES}

[1] Abraham-Fuchs, K., Christ, T., Schmidt, M., Schmidt, V., Schneider, S., \& Tiffe, S. (2003). System for medically assisting the occupants of a motor vehicle, U.S. Patent Application No. 10/689,952.
[2] Berghmans J., \& Anierscho M. V, (2014). Safety aspects of CNG cars, ProcediaEngineering, 2014, vol. 84, pp. $33-46$.

[3] Bird, J. A., Franz, M. P., Gilbert, H. M., Johnson, S. F., \& Shafer, M. R. (1997). Diagnosis method for vehicle systems, U.S. Patent No. 5,631,831. Washington, DC: U.S. Patent and Trademark Office.

[4] Emmanuel O., (2014). Basic Concepts of Expert System Shells and an efficient Model for Knowledge Acquisition, 2014, International Journal of Science and Research

[5] European Natural Gas Vehicle Association - Report http://www.ngva.eu/

[6] Farzaneh-Gord, M., Rahbari, H. R., \& Nikofard, H. (2012). The effect of important parameters on the natural gas vehicles driving range. Polish Journal of Chemical Technology, 14(4), 61-68.

[7] Hua, Z., Daowen, Z., Haibo, H., \& Jun, W. (2010). An experimental study of the safety and reliability of the dedicated devices for $\mathrm{CNG}$ vehicles.[Natural Gas Industry, 9, 027.

[8] Isermann, R. (2005). Model-based fault-detection and diagnosis-status and applications. Annual Reviews in control, 29(1), 71-85.

[9] Khan, M. I., Yasmin, T., \& Shakoor, A. (2015). Technical overview of compressed natural gas (CNG) as a transportation fuel. Renewable and Sustainable Energy Reviews, 51, 785-797.

[10] McNulty, M.C., et al.(1989). Expert vehicle control system." U.S. Patent No. 4,868,755.

[11] Negnevitsky, M. (2002). Artificial intelligence, a guide to intelligent system, First Edition, Pearson education.

[12] Oda, T., \& Katoh, E. (1992). Fault diagnosis expert system, U.S. Patent No. 5,127,005. Washington, DC: U.S. Patent and Trademark Office.

[13] Pan, W., \& Hongbing, X. (2007). Fault diagnosis expert system based on Bayesian network. Computer Measurement \& Control, 7, 855-857.

[14] Perrette L., \& Wiedemann H. K., (2007). CNG buses fire safety: learnings from recent accidents in France and Germany. Society of automotive engineer world Congress 2007, Detroit, United States.

[15] Regulation No 110 of the Economic Commission for Europe of the United Nations (UN/ECE) -Uniform provisions concerning the approval of I. specific components of motor vehicles using compressed natural gas (CNG) in their propulsion system; - II. vehicles with regard to the installation of specific components of an approved type for the use of compressed natural gas (CNG) in their propulsion system - (2011) http://www.unece.org/trans/main/ wp29/wp29wgs/ wp29gen/wp29fdocstts.html 
[16] Seyhan, N., Jasharllari, L., Kayapinar, M., \& Savac1, N. (2011). An unusual cause of cold injury: liquefied petroleum gas leakage. Ulus Travma Acil Cerrahi Derg, 17(6), 561-562.

[17] SRPS EN ISO 11439:2014. Gas cylinders - High pressure cylinders for the on-board storage of natural gas as a fuel for automotive vehicles (ISO 11439:2013) - http://www.iss.rs/

[18] SRPS ISO 19078:2009. Gas cylinders - Inspection of the cylinder installation, and requalification of high pressure cylinders for the on-board storage of natural gas as a fuel for automotive vehicles - http:// www.iss.rs/rs/standard/?natstandard_document_ $\mathrm{id}=23220$
[19] Sung, W., Lee, H., Lee, H., \& Lee, C. (2002). Numerical study for production performances of a methane hydrate reservoir stimulated by inhibitor injection. Energy Sources, 24(6), 499-512.

[20] Zamanian A., Ghafghazi I., \& Sabeti M.D. (2009). Cng cars safety in accidents (Case study: Iran, 21st International Technical Conference on the Enhanced Safety of Vehicles. v.2 